\title{
Lithium isotope enrichment by electrochemical pumping using solid lithium electrolytes
}

\author{
Shunsuke HONDA ${ }^{1}$, Kiyoto SHIN-MURA ${ }^{1}$ and Kazuya SASAKI ${ }^{1, \dagger}$ \\ ${ }^{1}$ Graduate School of Science and Engineering, Hirosaki University, 3 Bunkyo-cho, Hirosaki, Aomori 036-8561, Japan
}

\begin{abstract}
Concentrating ${ }^{6} \mathrm{Li}$ isotopes, which exist only approximately $7.6 \%$ in nature, to 40 to $90 \%$, is necessary for development of thermal fusion reactors, which are promising as next-generation base-load energy systems. We investigated the possibility of ${ }^{6} \mathrm{Li}$ enrichment by electrochemical pumping using $\mathrm{La}_{0.57} \mathrm{Li}_{0.29} \mathrm{TiO}_{3}$ solid lithium electrolytes. We also clarified the influence of potential application profiles on separation efficiency. Giving a potential difference to electrodes prepared on both sides of the electrolyte made the electrode on the lithium solution side positive and concentrated ${ }^{6} \mathrm{Li}$. The efficiency of lithium isotope enrichment was affected by the potential application profile. An intermittent potential application concentrates ${ }^{6} \mathrm{Li}$ with high efficiency. In an intermittent potential application in which the electrode on the lithium solution side was positive, an ${ }^{6} \mathrm{Li}$ concentration with higher efficiency was achieved when a small negative potential was applied to the lithium solution side electrode while suspending application of the positive potential.

(02018 The Ceramic Society of Japan. All rights reserved.
\end{abstract}

Key-words: Isotope enrichment, Lithium, Electrochemical pumping, Alternative potential application, Intermittent potential application

[Received November 10, 2017; Accepted January 21, 2018]

\section{Introduction}

The nuclear fusion reactor is a promising nextgeneration base-load energy system, because of its abundant fuel and excellent safety. Reaction between deuterium (D) and tritium (T) is selected for the nuclear fusion reactor because the temperature and pressure required are low. Deuterium is abundant in sea water and can be recovered easily at low cost. Since tritium scarcely exists in nature, on the other hand, it must be produced in the fusion reactor. ${ }^{1)}$ In the thermonuclear fusion reactors, now under development, lithium compounds called "tritium breeders" are entered into the neutron irradiation area of the furnace, and $\mathrm{T}$ is produced by a nuclear reaction between lithium and neutrons. To produce more $\mathrm{T}$ in the limited furnace space than that consumed in the nuclear fusion reaction, a reaction with ${ }^{6} \mathrm{Li}$ [Eq. (1)] rather than with ${ }^{7} \mathrm{Li}$ [Eq. (2)] should be used, because the neutron reaction cross-section of ${ }^{6} \mathrm{Li}$ is three orders of magnitude larger than that of ${ }^{7} \mathrm{Li}^{2}{ }^{2}$ Reactions with ${ }^{6} \mathrm{Li}$ are also accompanied by great heat generation, which can contribute to power generation. To supply a large enough amount of $\mathrm{T}$ to maintain a nuclear fusion reaction in the

Corresponding author: K. Sasaki; E-mail: k_sasaki@ hirosaki-u.ac.jp

$\$$ Preface for this article: Dol http://doi.org/10.2109/jcersj2. 126.P5-1 furnace, it is necessary to concentrate the ${ }^{6} \mathrm{Li}$ isotope, only approximately $7.6 \%$ of which is present in nature, to 40 to $90 \%:^{3)}$

$$
\begin{aligned}
& { }^{6} \mathrm{Li}+\mathrm{n} \rightarrow \mathrm{T}+\mathrm{He}+4.8 \mathrm{MeV} \\
& { }^{7} \mathrm{Li}+\mathrm{n} \rightarrow \mathrm{T}+\mathrm{He}+\mathrm{n}^{\prime}-2.5 \mathrm{MeV}
\end{aligned}
$$

The mercury amalgam method, which seems to be the only practical application available in the world today, imposes a large environmental burden. ${ }^{4), 5)}$ Thus, several new ${ }^{6} \mathrm{Li}$ enrichment methods have been studied. Taylor and Urey investigated a chemical exchange method using zeolites and reported a large fractionation factor for the lithium isotopes of 1.022.6) Glueckauf et al. studied isotope enrichment by the ion-exchange method. ${ }^{7)}$ The most studied isotope separation techniques are the solvent extraction and chromatography methods using crown ethers or polymerized crown ethers as lithium isotope receptors. ${ }^{8)-12)}$ Yan et al. reported a maximum value of 1.039 , however, while the fractionation factor for singlestage separation in most studies was small. Thus, to realize a sufficiently large separation factor, it is necessary to repeat a long and complicated batch-type process. Due to its poor cation selectivity, this requires solution of highpurity lithium as a starting material. There are also concerns about the environmental burden due to the use of large amounts of organic solvent. In recent years, Hoshino reported that it is possible to condense ${ }^{6} \mathrm{Li}$ by electrochemical pumping using an electrolyte membrane impregnated 
with a liquid electrolyte in a porous polymer membrane. ${ }^{11)}$ In this method, the fractionation factor for single-stage separation was small, but in theory it is possible to increase the ${ }^{6} \mathrm{Li}$ concentration easily by cascading. In practice, however, it has been difficult to realize this because the separation efficiency suddenly decreased due to leakage of the liquid electrolyte impregnated in the porous polymer during the operation. It is therefore difficult to separate the lithium isotope industrially and commercially separate lithium isotope by the methods studied so far, and it will be necessary to develop a new method for continuously separating lithium isotopes while imposing a small environmental burden. In this paper, we study the possibility of ${ }^{6} \mathrm{Li}$ enrichment by electrochemical pumping using lithium solid electrolyte $\mathrm{La}_{0.57} \mathrm{Li}_{0.29} \mathrm{TiO}_{3}$. The influence of the potential application profile on the separation efficiency is also clarified.

\section{Materials and methods}

The cell was prepared by applying a lattice-shaped Pt electrode (area: $20 \mathrm{~mm}$ square, line/space: $1 \mathrm{~mm} / 1 \mathrm{~mm}$ ) on either side of an LLTO dense sintered substrate (Toho Titanium Co., Ltd., $50 \mathrm{~mm} \times 50 \mathrm{~mm} \times 0.5 \mathrm{~mm}^{\dagger}$ ) via printing a of Pt paste (TR-7907, Tanaka Kikinzoku Kogyo Co., Ltd.) and firing at $900^{\circ} \mathrm{C}$ for $1 \mathrm{~h}$. Two Pt wires $\left(0.2 \mathrm{~mm}^{\varphi}\right)$ were attached to each electrode by firing a Pt paste (TR7603 T, Tanaka Kikinzoku Kogyo Co., Ltd.) at $900^{\circ} \mathrm{C}$ for $1 \mathrm{~h}$.

The cell was placed between an aqueous solution of lithium hydroxide $(1 \mathrm{~mol} / 1,130 \mathrm{ml})$ and pure water $(130$ $\mathrm{ml}$ ), as shown in Fig. 1. A silicone seal was used to prevent leakage. The lithium solution with a Li-concentration of $1 \mathrm{~mol} / \mathrm{l}$ was prepared by dissolving lithium hydroxide (Kanto Chemical Co., Inc., 98.0\%) in pure water. With an electrode in pure water used as a reference, constant potentials were applied to the electrodes in the lithium solution with different profiles. Table 1 summarizes the application

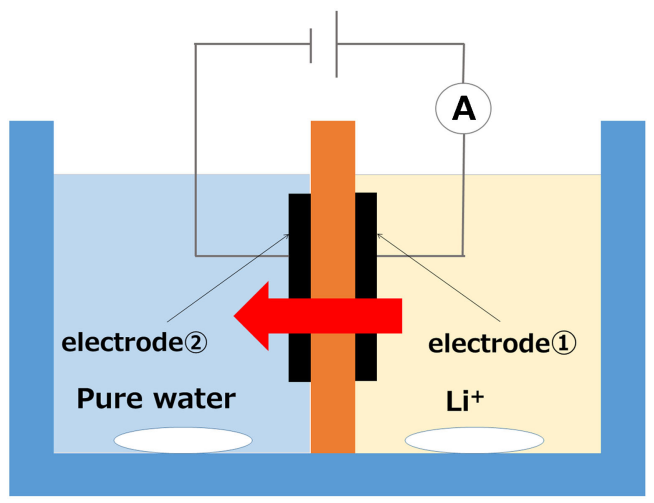

Fig. 1. Outline of experimental equipment and cell appearance. conditions for each profile. In Profile 1, a voltage of $2 \mathrm{~V}$ was applied continuously for $3600 \mathrm{~s}$. In Profile 2, an intermittent potential application $(2 \mathrm{~V}$-voltage application for $10 \mathrm{~s}$ and interruption for $10 \mathrm{~s}$ ) was repeated 360 times. In Profile 3, alternating potential applications ( $2 \mathrm{~V}$-voltage application for $10 \mathrm{~s}$ and $-1 \mathrm{~V}$-voltage application for $10 \mathrm{~s}$ ) were repeated 360 times. During the experiment, both solutions were thoroughly stirred constantly at the same speed using a stirrer. After application of the prescribed potential, the concentrations of ${ }^{6} \mathrm{Li}$ and ${ }^{7} \mathrm{Li}$ in lithium that moved into the pure water (concentration of lithium isotopes in electrode 2-side water) were measured by inductively coupled plasma mass spectrometry (ICP-MS) (DRC-e, Perkin Elmer, USA). For the ICP-MS measurement, the sample solution was filtered through a membrane filter (pore size $=0.45 \mu \mathrm{m}$ ). The filtrate was diluted with ultrapure water to a lithium concentration of approximately $100 \mu \mathrm{m} / \mathrm{L}$, nitric acid was added to make $0.7 \%$, and the sample was repeatedly analyzed 10 times. The standard deviations of the results obtained were 0.018 to 0.064 , and the relative standard deviations were 0.23 to $0.81 \%$. By the F-test and the t-test (significance level of two-sided test $=$ $5 \%$ ), it was confirmed that there were significant differences among the average values of the lithium concentration in each solution after recovery operations performed under different conditions.

\section{Results}

Gas generation by water electrolysis was confirmed for electrode 1 in the recovery operation.

Figure 2 shows the current change during continuous potential application under Profile 1. The insertion is an enlarged view for the initial $50 \mathrm{~s}$. The current sharply decreased in the initial few seconds to become a constant value.

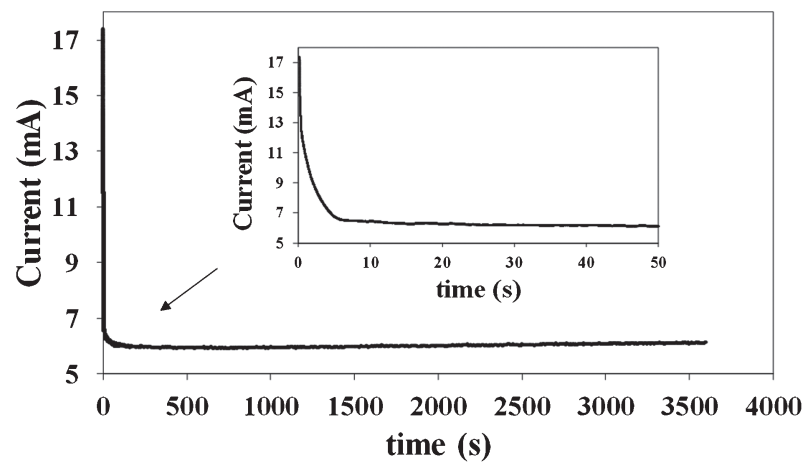

Fig. 2. Current-value change during continuous application of a constant voltage of $2 \mathrm{~V}$ (Profile 1). [Voltage: $2 \mathrm{~V}$ (vs electrode 2 in pure water); potential application time: $3600 \mathrm{~s}$; insertion: enlarged view of initial $50 \mathrm{~s}$ ].

Table 1. Potential application profile

\begin{tabular}{|c|c|c|c|c|c|c|c|}
\hline & \multicolumn{2}{|c|}{ Forward-voltage application } & \multirow{2}{*}{$\begin{array}{l}\text { Interval } \\
\text { time }(\mathrm{s})\end{array}$} & \multicolumn{2}{|c|}{ Reverse-voltage application } & \multirow{2}{*}{$\begin{array}{l}\text { Repetition count } \\
\text { time (s) }\end{array}$} & \multirow{2}{*}{$\begin{array}{l}\text { Total forward applied time } \\
\text { (s) }\end{array}$} \\
\hline & Applied voltage (V) & time $(\mathrm{S})$ & & Applied voltage (V) & time $(\mathrm{S})$ & & \\
\hline Profile 1 & 2 & 3600 & & & & 1 & 3600 \\
\hline Profile 2 & 2 & 10 & 10 & & & 360 & 3600 \\
\hline Profile 3 & 2 & 10 & & -1 & 10 & 360 & 3600 \\
\hline
\end{tabular}




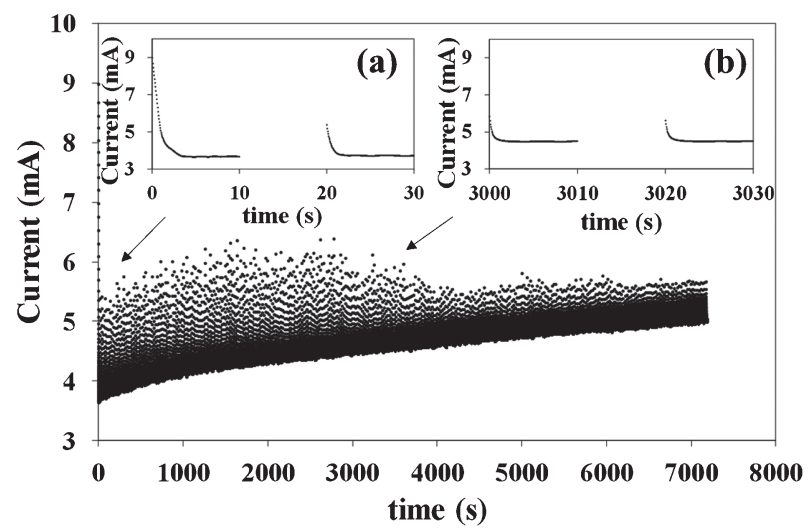

Fig. 3. Current-voltage change during intermittent. application of potential (Profile 2). [Voltage: 2V (vs electrode 2 in pure water); potential application time: $10 \mathrm{~s}$; rest time: $10 \mathrm{~s}$; repetition count time: 360 ] [a: initial $30 \mathrm{~s}$; b: 30 s (3000-3030 s)].

Figure 3 shows the current change during intermittent potential application under Profile 2 which repeats $2 \mathrm{~V}$ application for $10 \mathrm{~s}$ and interruption for $10 \mathrm{~s}$. The insertions are enlarged views related to $30 \mathrm{~s}$ immediately after the start of potential application and $30 \mathrm{~s}$ after application of the potential for $3000 \mathrm{~s}$. At the beginning of the potential application, the current value decreased abruptly to a constant value in $4 \mathrm{~s}$. A large current flowed again when the potential was reapplied after interruption of the potential application.

Figure 4 shows the change in the current value during potential application under Profile 3 which repeats application of an alternating potential of $2 \mathrm{~V}$ for $10 \mathrm{~s}$ and $-1 \mathrm{~V}$ for $10 \mathrm{~s}$. Figures 4(b) and 4(c) are enlarged views of $30 \mathrm{~s}$ immediately after the start of potential application and $30 \mathrm{~s}$ from $3000 \mathrm{~s}$ after the start of potential application. The current value when $2 \mathrm{~V}$ was applied abruptly decreased to a constant value in approximately $2 \mathrm{~s}$ immediately after the start of potential application.

Table 2 compares isotopic ratios in lithium migrating into pure water with electrochemical pumping under Profiles 1 to 3 . The table also shows the isotopic ratios of lithium in the lithium hydroxide aqueous solution before the experiment and the concentration factor (CF) calculated by Eq. (3). In all the electrochemical operations, the ${ }^{6} \mathrm{Li}$ concentration in lithium transferred into pure water was greater than the initial lithium hydroxide value. The concentration of ${ }^{6} \mathrm{Li}$ in lithium migrating into pure water with intermittent voltage application was larger than migrating with continuous application. When an alternating potential was applied, the ${ }^{6} \mathrm{Li}$ concentration increased further.

$$
C F=C_{\text {concentrated }} / C_{\text {initial }}
$$

[CF: Concentration factor, $C_{\text {concentrated: }}{ }^{6} \mathrm{Li}$-concentration in pure water, $C_{\text {initial }}{ }^{6} \mathrm{Li}$-concentration in initial $\mathrm{Li}$ solution]

\section{Discussion}

The potential application of $2 \mathrm{~V}$ (vs electrode 2) to electrode 1 caused migration of the $\mathrm{Li}^{+}$adsorbed on the surface of electrode 1 toward the opposite electrode (pure
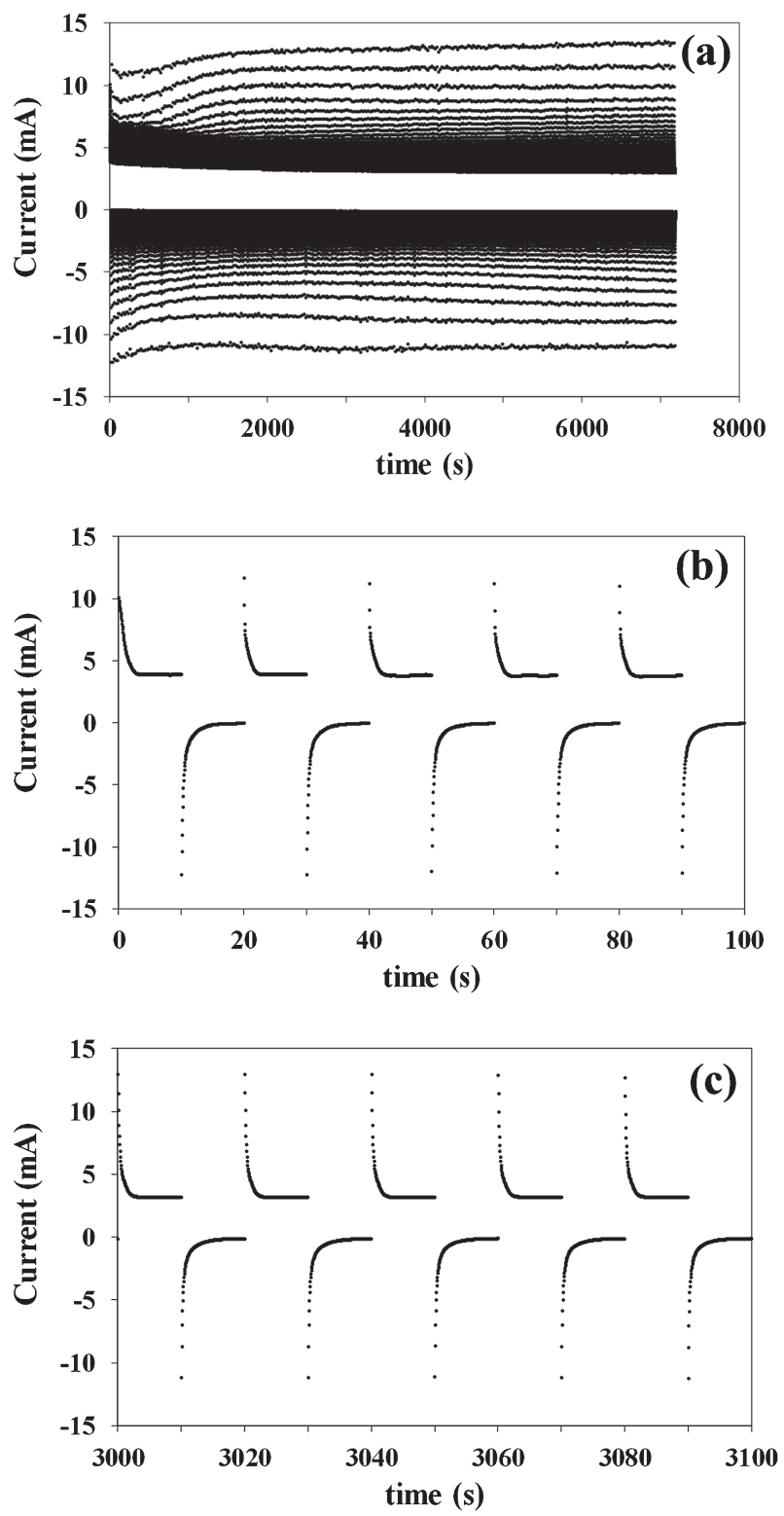

Fig. 4. Current-value change during alternate positive and negative voltage application (Profile 3). [Positive voltage: $2 \mathrm{~V}$; negative voltage: $1 \mathrm{~V}$ (vs electrode 2 in pure water); potential application time: $10 \mathrm{~s}$; rest time: $10 \mathrm{~s}$; repetition count time: 360$]$ [a: overall view, b: initial $100 \mathrm{~s}$, c: $100 \mathrm{~s}$ (3000-3100 s)].

Table 2. Comparison of lithium isotopic ratios

\begin{tabular}{cccl}
\hline & ${ }^{6} \mathrm{Li}$ concentration & ${ }^{7} \mathrm{Li}$ concentration & \multirow{2}{*}{$\mathrm{CF}$} \\
\cline { 2 - 3 } & $\mathrm{mol} \%$ & $\mathrm{~mol} \%$ & \\
\hline Initial LiOH solution & 7.85 & 92.14 & 1 \\
Profile 1 & 7.89 & 92.11 & 1.004 \\
Profile 2 & 7.95 & 92.05 & 1.012 \\
Profile 3 & 7.99 & 92.01 & 1.017 \\
\hline
\end{tabular}

water side electrode; electrode 2) with a lower potential along the electrochemical potential difference. It is assumed that the higher ${ }^{6} \mathrm{Li}$ concentration in lithium migrating into pure water with this electrochemicalpumping effect compared to the natural-isotope ratio is a result of different reaction rates for series reactions con- 
sisting of $\mathrm{Li}^{+}$migration in the lithium solution and its adsorption onto the electrode, and $\mathrm{Li}^{+}$diffusion in LLTO. For the chemical diffusion in the solid electrolyte via the vacancy mechanism, Vineyard predicted that the jump frequency of ions in the solid electrolyte was inversely proportional to the square root of the mass of the isotope element. ${ }^{13)}$ Based on measurement of lithium-ion conductivity in a lithium-ion electrolyte with a perovskite structure with different isotope ratios by the alternating current impedance method, Shioya et al. reported that the conductivity increases with the fraction of ${ }^{6} \mathrm{Li}$, although there is no difference in activation energy of the lithium-ion conduction. ${ }^{14)}$ That is, although the influence of isotopes on the rates of the $\mathrm{Li}^{+}$migration in the lithium solution, adsorption of $\mathrm{Li}^{+}$to the electrode surface and $\mathrm{Li}^{+}$dissolution into the electrolyte are not yet clarified, it can at least be estimated that the difference in the ion conduction velocity in the electrolyte due to the difference in mass of the isotopes is one of the causes of isotope enrichment.

It can be estimated that the large current generated immediately after application of the potential of $2 \mathrm{~V}$ and the subsequent small constant current correspond to the migration of a large amount of $\mathrm{Li}^{+}$adsorbed on the surface of electrode 1 toward the pure water and the steady flow of $\mathrm{Li}^{+}$toward electrode 1 (which is limited by $\mathrm{Li}^{+}$diffusion in the lithium solution), respectively. When an intermittent potential is applied under Profile 2, the ratio of lithium migrating in the former process (corresponding to the large current) is larger than that in the case of continuously constant potential application under Profile 1, and the ${ }^{6} \mathrm{Li}$ concentration is also high. This relationship suggests that ${ }^{6} \mathrm{Li}$ migrates faster than ${ }^{7} \mathrm{Li}$ when the large current is generated immediately after the start of the potential application. This phenomenon can be explained by the following mechanism. The isotope ratio in lithium supplied from the lithium solution to the surface of electrode 1 is equal to the natural ratio. That is, lithium in the solution with the natural isotopic ratio is adsorbed onto the empty adsorption site on the surface of electrode 1 generated by migration of lithium with application of the potential. The fraction of ${ }^{6} \mathrm{Li}$ in the lithium newly adsorbed onto the generated empty adsorption site is smaller than that of the lithium migrating to form the empty site. With continuous application of the constant potential, the fraction of ${ }^{6} \mathrm{Li}$ in the lithium adsorbed onto the surface of electrode 1 gradually decreases. As a result, it is difficult to concentrate ${ }^{6} \mathrm{Li}$ using high efficiency with continuous potential application. In the case of intermittent potential application under Profile 2, on the other hand, the electrical potential gradient attracting $\mathrm{Li}^{+}$adsorbed on the surface of electrode 1 toward the counter electrode disappears due to interruption of the potential application. The resulting dissociation and adsorption of $\mathrm{Li}^{+}$onto the electrode surface during the interruption of the potential application brings the isotope ratio in the lithium adsorbed on the electrode surface closer to the natural ratio. When application of the $2 \mathrm{~V}$-potential is restarted, ${ }^{6} \mathrm{Li}$ is dissolved into the electrolyte at a higher rate at electrode 1 , where lithium is adsorbed at the natural isotope ratio (its ${ }^{6} \mathrm{Li}$ fraction is higher than that in the continuous constant potential application). Intermittent potential application can therefore concentrate ${ }^{6} \mathrm{Li}$ with high efficiency.

When alternating voltages of $2 \mathrm{~V}$ and $-1 \mathrm{~V}$ (vs electrode 2) were applied to electrode 1 under Profiles 3, ${ }^{6} \mathrm{Li}$ was enriched at a higher rate. This phenomenon can be explained by the following mechanism: with application of $-1 \mathrm{~V}$-potential, the current that had flowed for a short time immediately after the start of the application stopped immediately. While the current is not flowing, $\mathrm{Li}^{+}$in the solution is attracted to electrode 1 along the potential, because the potential of the electrode 1 is negative. The ions with a small mass $\left({ }^{6} \mathrm{Li}^{+}\right)$are attracted at an acceleration greater than ${ }^{7} \mathrm{Li}^{+}$, and the fraction of ${ }^{6} \mathrm{Li}$ in lithium adsorbed onto the surface of electrode 1 becomes higher than the natural ratio. Applying the potential of $2 \mathrm{~V}$ again to electrode 1 , to which ${ }^{6} \mathrm{Li}$ was adsorbed at a high concentration, causes more ${ }^{6} \mathrm{Li}$ to migrate into the pure water.

\section{Conclusions}

${ }^{6} \mathrm{Li}$ can be concentrated by using a cell with a lithiumconductive solid electrolyte with Pt electrodes and introducing a potential difference that makes the lithium solution side electrode positive. The ${ }^{6} \mathrm{Li}$ concentration efficiency changes depending on differences in the potential application profile. Compared to continuous constant potential application, intermittent potential application concentrates ${ }^{6} \mathrm{Li}$ with higher efficiency. Applying a small negative potential to the lithium solution side electrode in the intermittent potential application, in which the lithium solution side electrode is positive, while suspending application of the positive potential concentrates ${ }^{6} \mathrm{Li}$ more efficiently.

Acknowledgement This work was supported by a Study Grant from the JSPS KAKENHI (grant No. 16H04624).

\section{Reference}

1) K. Tobita, S. Nishio, H. Tanigawa, M. Enoeda, T. Isono, H. Nakamura, D. Tsuru, S. Suzuki, T. Hayashi, K. Tsuchiya, T. Hayashi and T. Nishitani, J. Nucl. Mater., 386-388, 888-892 (2009).

2) Y. Murakami, A. Danno and M. Kobayashi, (Eds.) Radiation data book (1st ed.), Chijinshokan, Tokyo, (1982). [in Japanese].

3) S. Nishio, J. Ohmori, T. Kuroda, K. Tobita, M. Enoeda, D. Tsuru, T. Hirose, S. Sato, Y. Kawamura, H. Nakamura and M. Sato, Fusion Eng. Des., 81, 12711276 (2006).

4) G. N. Lewis and R. T. Macdonald, J. Am. Chem. Soc., 58, 2519-2524 (1936).

5) K. Okuyama, I. Okada and N. Saito, J. Inorg. Nucl. Chem., 35, 2883-2895 (1973).

6) T. I. Taylor and H. C. Urey, J. Chem. Phys., 6, 429-438 (1938).

7) E. Glueckauf, K. H. Barker and G. P. Kitt, Discuss. Faraday Soc., 7, 199-213 (1949).

8) F. Yan, H. Pei, Y. Pei, T. Li, J. Li, B. He, Y. Cheng, Z. Cui, D. Guo and J. Cui, Ind. Eng. Chem. Res., 54, 
3473-3479 (2015).

9) M. Davoudi and M. H. Mallah, Ann. Nucl. Energy, 62, 499-503 (2013).

10) K. Nishizawa, T. Takano, I. Ikeda and M. Okahara, Sep. Sci. Technol., 23, 333-345 (1988).

11) K. Nishizawa, H. Watanabe, S. Ishino and $M$. Shinagawa, J. Nucl. Sci. Technol., 21, 133-138 (1984).
12) T. Hoshino and T. Terai, Fusion Eng. Des., 86, 21682171 (2011).

13) G. H. Vineytard, J. Phys. Chem. Solids, 3, 121-127 (1957).

14) S. Shioya, T. Nagasaki, T. Matsui and H. Shigematsu, Solid State Ionics, 161, 55-59 (2003). 